\title{
OBITUARIO
}

\section{Luis Ángel Ramorino Meschi (1935 - 2020)}

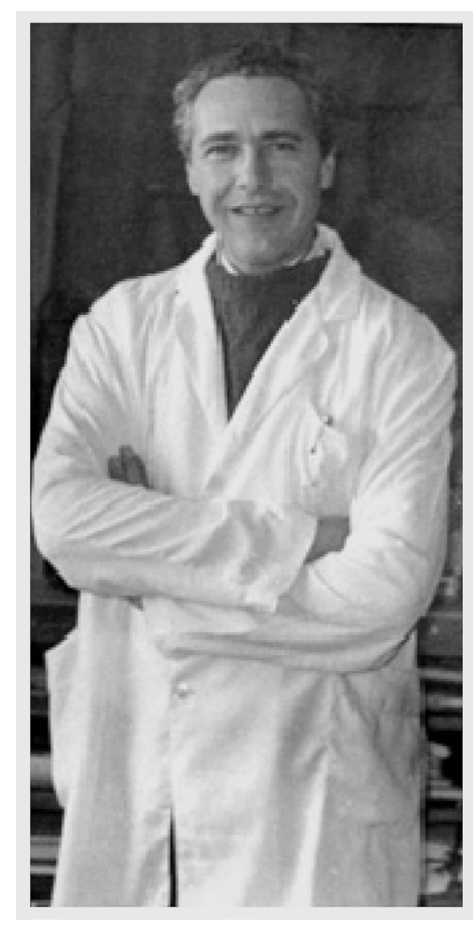

Una gran tristeza nos embargó al saber del fallecimiento de nuestro amigo y colega Luis Ramorino Meschi, para sus cercanos Luigi o Lucho, ocurrido el 26 de mayo de 2020, después de haber mantenido bajo control por mucho tiempo una enfermedad que finalmente ganó la batalla. Se desempeñó por más de 40 años en la academia, iniciando su carrera académica en el Instituto Pedagógico de la Universidad de Chile, para posteriormente incorporarse como Ayudante de Laboratorio a la Estación de Biología Marina de Montemar, actual Facultad de Ciencias del Mar y de Recursos Naturales de la Universidad de Valparaíso. Se desempeñó en diversos cargos, hasta alcanzar el de Director de esta institución.

Lo recordamos como un hombre sobrio, de carácter amable, acogedor, de buen trato, ordenado y frugal. Para las secretarias de Montemar, trabajar con él fue muy grato: un jefe de quien se aprendió a tener actitud para resolver cualquier imprevisto, jamás olvidaba algo que hacer, atento, empático. Siempre reconoció que era parte de un equipo de trabajo. Con menos tecnología que hoy tenía sus registros al día y llamaba la atención cómo podía hacer tantas cosas a la vez: clases, laboratorio, atención alumnos, dirección de una carrera.

El detalle lo caracterizaba, desde el saludo cada mañana hasta una ceremonia de titulación de sus alumnos, en donde ningún detalle faltaba, flores compradas por él mismo para adornar y hacer más hermosa la ceremonia. Jamás olvidó un saludo en el Día de la Secretaria o en la Navidad y sus huevitos de chocolate eran siempre esperados para Pascua de Resurrección. Era reconocido por sus hermosos suéteres tejidos por su señora y tenía buena mano para hacer queques, con los que aparecía en nuestras oficinas-laboratorios algún lunes, para acompañar un té o café. Era difícil de convencer para cambiar sus ideas a no ser que lo superaran los argumentos y estaba siempre dispuesto a enseñar y traspasar sus conocimientos. 
Luis Ramorino nació en Santiago, el 10 de diciembre de 1935. Estudió Pedagogía en Biología y Química en el Instituto Pedagógico de la Universidad de Chile, entre 1956 y 1961, titulándose de Profesor de Estado en Biología y Química. Con su tesis "Aspectos biológicos de un gasterópodo de la zona intercotidal (Littorina peruviana)", inició su carrera en malacología, la que mantuvo por cerca de 40 años. En 1959, ingresó a la Universidad de Chile como Ayudante de Laboratorio en la Cátedra de Biología en la Facultad de Filosofía y Educación y jubiló en 2008, como Profesor Titular de la Universidad de Valparaíso (ex Universidad de Chile, sede Valparaíso).

En 1962, se desempeñó como Profesor de Laboratorio de Biología Marina, de la Carrera de Biología Marina, en la Facultad de Filosofía y Educación. Ese mismo año, gracias a una beca UNESCO, partió a Europa junto a su señora Paulina Venzano, al Laboratorio de Biologia Marina de la Universidad de Copenhague, en Elsinor, Dinamarca, para un entrenamiento en el estudio de larvas de moluscos, bajo la dirección del Dr. Gunnar Thorson. En 1963, realizó estadías en los principales laboratorios de ciencias del mar en Suecia, Noruega, Escocia, Gran Bretaña, Holanda, Alemania, Italia y Francia.

A su regreso a Chile, se desempeñó como Profesor de Zoología de la primera promoción de biólogos marinos (1964) de la Universidad de Chile y también como Profesor en un curso de Malacología, en la Facultad de Ciencias de la misma Universidad.

Durante la misma década participó en los cruceros del buque oceanográfico "Explorador" de la Universidad de Chile, demostrando su aptitud náutica, como jefe científico de la prospección del fenómeno El Niño Oscilación Sur (ENOS) en interacción con la pesquería del norte de Chile. También instaló el Laboratorio de Malacología en Montemar y que funciona hasta hoy. En alguna oportunidad él relató que para dedicarse al estudio de las larvas de moluscos necesitaba un microscopio de muy buena calidad óptica y como no disponía de uno, decidió contarle de esta dificultad al Dr. Thorson quien contactó a las autoridades de la Universidad y así consiguió su microscopio Leitz Ortholux.

En el Laboratorio de Malacología recibió a colegas de otras universidades del país y a profesionales extranjeros en entrenamiento en moluscos, dirigió tesis de pregrado y supervisó prácticas profesionales a estudiantes de Biología Marina tanto de la misma universidad como de otras. Ocupó diversos cargos en el ámbito universitario, desempeñándose como Director del Departamento de Oceanología (1975-1978) y posteriormente como Director del Instituto de Oceanología (1982-1986) en Montemar, en ese entonces dependientes de la Universidad de Chile. Fue Coordinador de la carrera de Biología Marina entre 1991 y 2001 y luego Director de la Escuela de Biología Marina, entre 2001 y 2008. En este cargo, participó como uno de sus artífices en el diseño del proyecto MECESUP "Programa para la Movilidad de Estudiantes y Coordinación Académica de las Carreras de Biología Marina”, con la formación de las Red ANBIMA (Red Nacional de Carreras de Biología Marina). Además, fue Director - Editor de la Revista de Biología Marina entre 1968 y 1979 y nuevamente, entre 1982 y 1995. Participó como socio fundador, en 1979, de la Sociedad Chilena de Malacología, hoy Sociedad Malacológica de Chile.

En conjunto con sus actividades administrativas, dirigió diversos proyectos de investigación sobre biología reproductiva y desarrollo larval de moluscos, financiados por la Dirección de Investigación de la Universidad de Chile y por CONICyT resultando en publicaciones consideradas clásicas, tales como "Biología de moluscos cultivados en América Latina", "Ciclo reproductivo de Concholepas concholepas en la zona de Valparaíso", "Conocimiento científico actual sobre Concholepas concholepas", "Pelecypoda del fondo de la bahía de Valparaíso", "Desarrollo larval y postlarval de Perumytilus purpuratus", "Larvas de Mytilidae de Chile", entre otras.

Entre 1987 y 1999, se desempeñó como asesor científico en el Departamento de Asuntos Internacionales de la Dirección del Territorio Marítimo (DIRECTEMAR), en temas de protección del medio marino, áreas costeras en Chile y plan de acción frente al cambio climático, siendo autor de varios informes científicos en estos temas. En el ámbito internacional, se desempeñó como Coordinador en el Programa Coordinado de Investigación Vigilancia y Control de la Contaminación Marina en el Pacífico Sudeste (CONPACSE), de la Comisión Permanente del Pacífico Sur (CPPS) y del Programa de las Naciones Unidas para el Medio Ambiente (PNUMA), participando con ponencias en diversas reuniones internacionales como representante de Chile. 


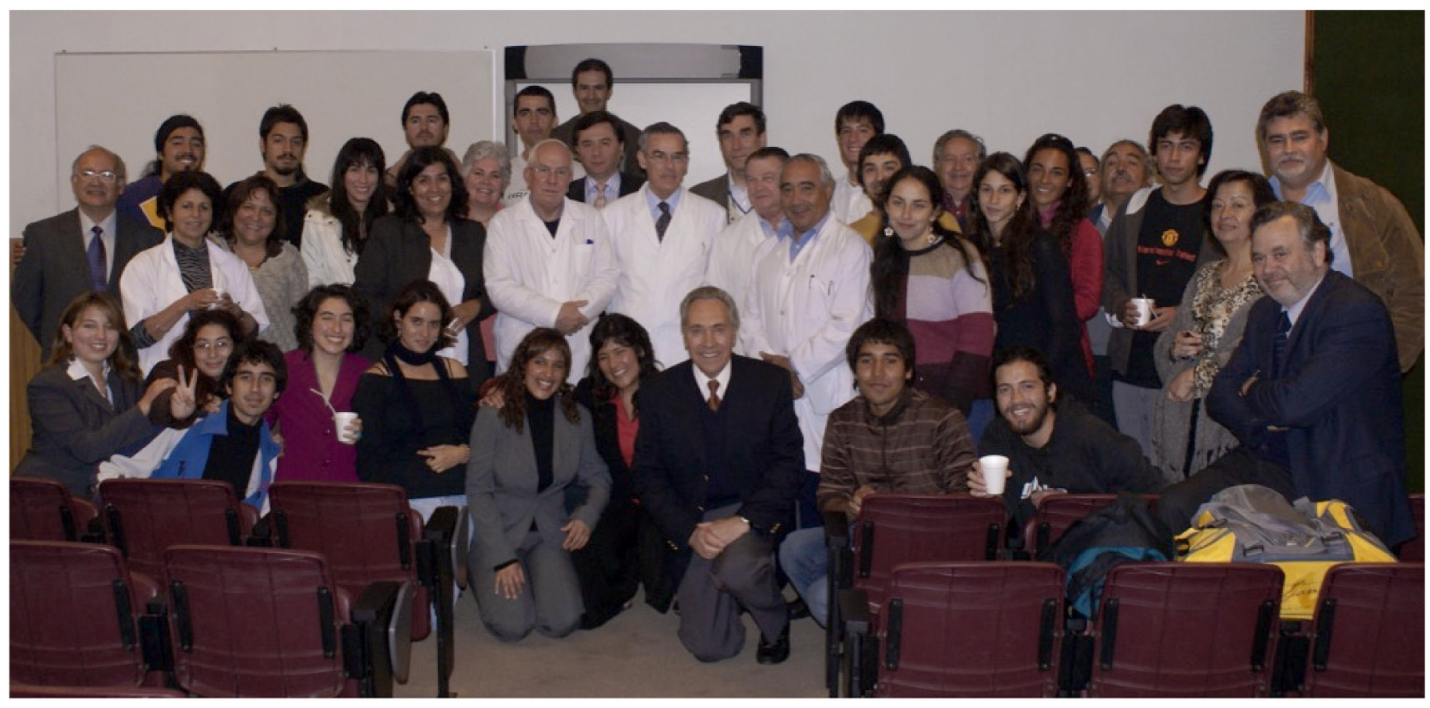

Ceremonia de homenaje a Luis Ramorino en su retiro de la Universidad de Valparaíso (2008)

Después de haber jubilado, nuestro colega iba cada cierto tiempo a Montemar y pasaba a saludar a nuestras oficinas para enterarse de las últimas novedades. Ahora él forma parte de la historia de Montemar para siempre.

Este obituario se enriqueció con los aportes de las secretarias de Montemar: Carmen Gloria Arancibia, Patricia Ahumada y Jaqueline Rivera. Además, por las comunicaciones recibidas en Montemar, de parte de sus colegas Eduardo Reyes, Pablo Muñoz, Roberto Prado, Carlos Gallardo y Eduardo Tarifeño.

Con motivo de las expresiones de sus colegas, su hija hizo llegar este mensaje: Cada vez que leo las palabras de los colegas de papá, me lleno de alegría y orgullo. Las agradezco porque en algo mitigan el dolor de su pérdida. Nos hace recordar con nostalgia los días en que mi padre le contaba a mis hijos (sus nietos), estas mismas historias y sus aventuras en el buque Explorador. Por favor pediría hacer extensivos mis agradecimientos a todos. Muchas gracias por las bellas palabras que todos han dedicado a mi padre. Saludos, Ingrid Ramorino $V$.

\section{${\text { Bernardita Campos } \text { Maia }^{{ }^{*}} \text { y Fernando Balbontín Cavada }}^{1}$}

${ }^{1}$ Escuela de Biología Marina, Facultad de Ciencias del Mar y de Recursos Naturales Universidad de Valparaíso, Viña del Mar, Chile *bernardita.campos@uv.cl 